\title{
Luta pela terra e processo de reforma agrária no Sertão Paraibano
}

\author{
Struggle for land and process of agrarian reform in the Sertão from Paraiba \\ Lucha por tierra y proceso de reforma agraria en el Sertão ${ }^{1}$ Paraibano
}

Saul Ramos de Oliveira ${ }^{2}$

Roberto de Sousa Miranda ${ }^{3}$

\section{Resumo}

OLIVEIRA, Saul Ramos de; MIRANDA, Roberto de Sousa. Luta pela terra e processo de reforma agrária no Sertão Paraibano. Rev. C\&Trópico, v. 43, n. 2, p. 111-124, 2019. DOI: https://doi. org/10.33148/Cetropicov43n2(2019)art.5
\end{abstract}

Este artigo tem como objetivo analisar como se deu a formação do espaço agrário da Mesorregião do Sertão Paraibano. O Sertão Paraibano foi, historicamente, caracterizado pela prática da pecuária, em vastas áreas, e pelo cultivo do algodão. Em ambas as atividades, a concentração de terras ocasionou a exclusão de grande parte dos trabalhadores rurais, quadro que permanece até os dias atuais. Para analisar a concentração de terras no Sertão Paraibano, foram utilizados dados do Instituto Nacional de Colonização e Reforma Agrária (INCRA), contendo o número de assentamentos criados na mesorregião do Sertão paraibano, que estão inseridos no Sistema Informatizado de Projetos de Reforma Agrária (SIPRA), e correspondem ao período que vai de 01/01/1900 a 31/12/2011. Foi verificado que, mesmo havendo projetos de reforma agrária no Sertão paraibano, a terra ainda continua concentrada em grande parte da mesorregião.

Palavras-chave: Latifúndio. Semiárido. Nordeste. Concentração de terras. Agricultura Familiar.

\section{Abstract}

OLIVEIRA, Saul Ramos de; MIRANDA, Roberto de Sousa. Struggle for land and process of agrarian reform in the Sertão from Paraiba. Rev. CઐrTrópico, v. 43, n. 2, p. 111-124, 2019. DOI: https://doi.org/10.33148/Cetropicov43n2(2019)art.5

This his article aims to analyze how the agrarian space of the Mesoregion of the Sertão from Paraiba took place. Sertão from Paraíba has historically been characterized by the practice of cattle ranching in large areas and the cultivation of cotton. In both activities, the concentration of land led to the exclusion of most rural workers, a situation that remains to this day. To analyze land concentration in the Sertão from Paraíba, we used data from the National Institute of Colonization and Agrarian Reform (INCRA) containing the number of settlements created in

\footnotetext{
una región del interior Paraibano muy afectada por la sequía.

2 Doutorando em Ciências do Solo pela Universidade Federal da Paraíba. Engenheiro Agrônomo, Mestre em Horticultura tropical pela Universidade Federal de Campina Grande. E-mail: saul.oliveira.ramos@hotmail.com. Orcid: https://orcid.org/0000-0002-2804-6671

3 Doutor em Ciências Sociais. Professor do Programa de Pós-Graduação em Ciências Sociais da Universidade Federal de Campina Grande. E-mail: robertosmiranda@yahoo.com.br. Orcid: https://orcid.org/0000-0003-2412-7914
} 
the mesoregion of the Sertão from Paraiba inserted in the Computerized System of Agrarian Reform Projects (SIPRA), dated from 01/01/1900 to 12/31/2011. It was found that even with land reform projects in the Sertão from Paraíba, the land is still concentrated in much of the mesoregion.

Keywords: Latifundium. Semiarid. Northeast. Land concentration. Family farming.

\section{Resumen}

OLIVEIRA, Saul Ramos de; MIRANDA, Roberto de Sousa. Lucha por tierra y proceso de reforma agraria en el Sertão Paraibano. Rev. C\&Trópico, v. 43, n. 2, p. 111-124, 2019. DOI: https://doi. org/10.33148/Cetropicov43n2(2019)art.5

Este artículo tiene por objetivo analizar como tuvo lugar la formación del espacio agrario de la Mesorregión Sertão Paraibano. El Sertão Paraibano se ha caracterizado históricamente por la práctica del ganado en grandes áreas y el cultivo de algodón. En ambas actividades, la concentración de tierras condujo a la exclusión de la mayoría de los trabajadores rurales, una situación que continúa hasta nuestros días. Para analizar la concentración de la tierra en el Sertão Paraibano, se utilizaron datos del Instituto Nacional de Colonización y Reforma Agraria (INCRA), que contienen el número de asentamientos creados en la Mesorregión del Sertão Paraibano, que se insertan en el Sistema Computarizado de Proyectos de Reforma Agraria (SIPRA) y corresponden al período de 1/1/1900 a 31/12/2011. Se descubrió que incluso con proyectos de reforma agraria en Paraíba, la tierra todavía se concentra en gran parte de la mesorregión.

Palabras clave: Latifundio. Semiárido. Nordeste. Concentración de tierras. Agricultura Familiar.

\section{Introdução}

A estrutura agrária brasileira sempre foi marcada por uma grande concentração de terra, associada a um modelo agroexportador de monoculturas. Essas características tiveram início desde a colonização brasileira, primeiro com as capitanias hereditárias, depois as sesmarias, até a modernização no campo e a formação dos latifúndios modernos. Por todo o processo histórico da formação e desenvolvimento do campo brasileiro, a exclusão dos pobres do campo sempre foram marcas visíveis nesse processo, ocasionando embates históricos entre excluídos e opressores.

Nesse contexto, a formação dos espaços agrários no Brasil vem se modificando cada vez mais com a ação das lutas dos vários movimentos, que se caracterizam como uma reação à estrutura fundiária concentradora. É importante frisar que a ação dos movimentos de luta já é bastante antiga nos lugares que serviram de base para os movimentos atuais.

A Paraíba é um estado litorâneo que teve a organização e a expansão do seu espaço agrário atrelado aos interesses da cana de açúcar. O conhecimento das dinâmicas agrárias, ao longo da história desse estado, é de fundamental importância 
para as análises atuais de suas relações de trabalho e econômicas que envolvam o seu espaço agrário. O Sertão paraibano, mesorregião desse Estado, é caracterizado por uma histórica concentração de terras onde ainda se perpetuam antigas relações de trabalho submissas aos latifundiários como: sistemas de moradores, arrendatário e meeiros. O objetivo deste trabalho foi fazer uma análise da estrutura fundiária do Sertão paraibano, utilizando dados do Instituto Nacional de Colonização e Reforma Agrária (INCRA), contendo o número de assentamentos criados na mesorregião do Sertão paraibano, que estão inseridos no Sistema Informatizado de Projetos de Reforma Agrária (SIPRA), e correspondem ao período que vai de $1 \% / 1 / 1900$ a $31 / 12 / 2011$.

\section{Referencial teórico}

\subsection{Formação do espaço agrário no sertão paraibano}

A criação de gado, no Litoral, se restringia, apenas, a pequenas extensões nos interiores dos engenhos e tinha a finalidade de abastecer o mercado de carne do Litoral e do próprio engenho, além disso, fornecia animais para trabalhar nas tarefas diárias. Com o aumento do consumo de carne do Litoral e uma crescente demanda por animais de trabalho, os rebanhos bovinos cresceram e, conflitos envolvendo lavradores e criadores de gado não tardaram acontecer (ANDRADE, 2005).

Esses conflitos resultaram na separação entre a criação de gado e o cultivo de cana. Sob pressão dos canaviais, a pecuária teve que procurar novas terras, transformando-se na atividade que desbravou o Sertão. A coroa portuguesa, entre os séculos XVI e XVII, realizava vastas concessões de terras para aqueles que desbravassem o Sertão. Entre as famílias de desbravadores, ganhou destaque a de Garcia d’Ávila, também conhecida como Casa da Torre, composta por pecuaristas que introduziram seus rebanhos pelo Sertão Paraibano, sendo de fundamental importância para a conquista da mesorregião (ALVEAL; BARBOSA, 2015).

Outro fator preponderante para a interiorização do estado foi a crise do setor açucareiro. Muitos trabalhadores desempregados começaram a migrar para o Sertão, na esperança de melhor qualidade de vida na pecuária e pequena agricultura (PEREIRA, 2017).

A primeira via de penetração para o interior, no estado da Paraíba, foi seguindo rio Paraíba. Ao longo de suas margens, foram instalados currais e fazendas de gado, dando origem a vários núcleos populacionais como: Pilar, São Miguel, Itabaiana, Mogeiro, etc. Merecendo destaque o capitão-mor Teodósio de Oliveira Ledo, que desbravou grandes extensões de área (MOREIRA;TARGINO, 1996).

O sistema de pecuária, no Sertão, consistia na criação de gado em sistema de pastejo extensivo em campo aberto. Devido à pobreza das pastagens naturais da caatinga, à existência de uma estação seca prolongada e à utilização de técnicas de criação muito rudimentares, eram necessários muitos hectares para alimentar os rebanhos bovinos (ANDRADE, 2005). 
A organização do trabalho no Sertão foi por meio do trabalho livre e escravo, mas com predominância do livre. Entre os trabalhadores livres podemos citar os carreiros, que transportavam mercadorias nos seus carros de bois; os tangedores, que evitavam as disparadas das boiadas auxiliando os vaqueiros e, finalmente, o vaqueiro, figura principal da pecuária Sertaneja. Cabia ao vaqueiro: cuidar do rebanho, administrar a fazenda na ausência do dono e dar ordens aos trabalhadores e agregados. Seu pagamento era por meio de quarteação, ou seja, o vaqueiro recebia um quarto dos bezerros, potros e cabritos nascidos na fazenda (ANDRADE, 2005).

Embora a pecuária sertaneja tenha na base o latifúndio, Moreira e Targino (1996) enfatizam que essa atividade deu melhores acessos à posse da terra para os trabalhadores livres pobres. Vários vaqueiros se tornaram fazendeiros graças ao seu modo de pagamento, além disso, a pecuária abriu mais espaço para arrendatários e meeiros, devido às grandes áreas que ocupavam, tornando-se de difícil controle para um fazendeiro só.

No entanto, a vida dos trabalhadores livres, também não era fácil. Muitos deles tinham que sobreviver sem a ajuda dos donos das fazendas. Necessitavam produzir seus utensílios, roupas, além de produzir seu próprio alimento, enfrentando a severidade do clima sertanejo (NOGUEIRA e SIMÕES, 2009).

O comércio sertanejo era relacionado à atividade colonial, com objetivo de atender o mercado interno Paraibano. Além da carne, do leite e dos animais de trabalho, o Sertão também produzia vários artefatos de couro, como: chapéus, roupas, calçados, arreios, camas, etc. Logo, a pecuária foi de fundamental importância para o desenvolvimento do Sertão (MOREIRA, TARGINO, 1996; NOGUEIRA, SIMÕES, 2009).

Também houve agricultura no Sertão paraibano. A cultura do algodão foi expandida do Agreste e ocupou um importante papel na economia do sertão paraibano. Para Aranha (1991), seu maior desenvolvimento na Paraíba ocorreu no século XVIII, devido a fatores como: Crescimento do progresso técnico da indústria têxtil inglesa, afastamento dos Estados Unidos do mercado mundial em decorrência da Guerra da Independência, crescimento populacional e, consequentemente, maior necessidade de tecidos, entre outros.

Na década de 1930, a cotonicultura sertaneja é impulsionada por meio da vinda das multinacionais SANBRA e ANDERSON CLEYTON. Essas empresas atuavam na compra, venda e beneficiamento do algodão em várias cidades da mesorregião (ARANHA, 1991).

As culturas de subsistências também fizeram parte das lavouras Sertanejas. Muitos trabalhadores livres, como arrendatários, parceiro e meeiros, cultivavam pequenas lavouras diversificadas de milho e feijão, entre outros vegetais, nas áreas mais férteis e nos leitos dos rios sazonais (CARON; SABOURIN, 2003).

O processo desorganizado e excludente de concessão de terras pela coroa portuguesa, a necessidade do uso de grandes áreas de pastejo, para os rebanhos, e a falta de projetos de reforma agrária, proporcionaram uma enorme concentração de terra que se perpetua até os dias de hoje. É muito comum ver grandes áreas abandonadas ou improdutivas. A pecuária não é mais praticada em grandes áreas e sim em pequenas 
e médias propriedades. O cultivo do algodão é quase inexistente, foi substituído por culturas de subsistência como milho e feijão. Em propriedades ribeirinhas com disponibilidade de irrigação é mais comum, atualmente, o cultivo de banana, coco e forrageiras para alimentação de bovinos e ovinos.

O latifúndio também causou grande êxodo rural no sertão paraibano, acarretando vários problemas. Muitos agricultores saíram do campo devido à falta de emprego, indo em direção ao Sul e Sudeste para trabalhar em setores como: construção civil, mercado informal de vendas, etc. A falta de trabalhadores no campo, em muitos casos, inviabilizou a produção de médios produtores, por conta dos elevados preços das diárias cobradas pelos poucos trabalhadores rurais que ainda permanecem no campo, o que também vem desestimulando vários médios produtores, ocasionando ainda mais desemprego e estagnação econômica.

\subsection{Reforma agrária no sertão paraibano}

A luta pela terra na Paraíba começa ainda na década de 1950, com a criação das ligas camponesas na Zona da Mata paraibana. Com o golpe militar de 1964, as ligas são desarticuladas e o movimento de luta pela terra sofre retração, contudo, com a redemocratização do Brasil na década de 1980, os movimentos sociais de luta pela terra no campo voltam a atuar e passam a pressionar o governo pela reforma agrária.

Conflitos pela terra no Sertão surgiram de forma mais tardia do que na Zona da Mata, contudo, com a redemocratização do país, avançam em direção à região semiárida. Moreira (1997) destaca diversos ou muitos conflitos pela terra em vários municípios do Sertão paraibano, como: Riacho dos Cavalos, em 1985; Cacimba de Areia, em 1986; São José do Rio do Peixe, em 1987; Triunfo, em 1990; Jericó, em 1992, entre outros.

O primeiro movimento de luta pela terra no Sertão começou com grupos oriundos da igreja católica, as CEBs (Comunidades Eclesiais da Base), e, posteriormente, com a CPT (Comissão Pastoral da Terra), que ajudaram trabalhadores de vários municípios (Jericó, Triunfo, Bonito de Santa Fé, e Riacho dos Cavalos). Esses agricultores familiares pediam apoio para a demarcação das terras na bacia dos açudes públicos situados nesses municípios, na década de 80 , que haviam sido griladas (OLIVEIRA, 2013).

Também na década de 1980 surge o Movimento dos Sem Terra (MST), como uma nova expressão de luta pela terra. O primeiro congresso do MST na Paraíba foi em 1985, reunindo 25 agricultores familiares, marcando sua fundação no Estado. Até os dias atuais, o MST tem sido um importante movimento de organização e politização dos agricultores para a realização da Reforma Agrária (OLIVEIRA, 2013).

A ação desses movimentos vem contribuindo para modificar a paisagem agrária da Paraíba e da mesorregião do Sertão, pressionando as autoridades governamentais para acelerar a reforma agrária no estado e no Sertão. Diante disso, o processo de reforma agrária no Sertão paraibano, que se iniciou no final da década de 1980, com apoio dos movimentos sociais de luta como a CPT e o MST, vem mudando o cenário da região e realizando o sonho de vários agricultores familiares que desejavam terras. 
Entre os anos 1989 e 2013 foram registradas, no estado da Paraíba, 204 ocupações de terra, participando do processo 22.774 famílias (cerca de 90 mil pessoas). $\mathrm{O}$ sertão do estado teve grande destaque na luta pela terra: foram verificadas 61 ocupações (29,9\% do total), envolvendo 6.246 famílias (27\% do total), sendo a microrregião de Sousa com o maior número de ocupações (GETEC, 2015).

\section{Metodologia}

Para realizar um quadro da estrutura fundiária do Sertão paraibano, foi realizada uma análise dos dados do Instituto Nacional de Colonização e Reforma Agrária (INCRA), contendo o número de assentamentos criados na mesorregião do Sertão paraibano, que estão inseridos no Sistema Informatizado de Projetos de Reforma Agrária (SIPRA), e correspondem ao período que vai de 01/01/1900 a 31/12/2011.

Com essas informações, foi realizada uma tabela indicando o município onde foi realizado o projeto de assentamento, nome do assentamento, data de criação, número de famílias assentadas, capacidade do assentamento por número de famílias, e a área (em ha) dos assentamentos.

\section{Análise e discussão dos resultados}

De acordo com os dados do Incra, dos 83 municípios, distribuídos em sete microrregiões, só foram realizados projetos de assentamentos rurais em 28 , totalizando 60 assentamentos criados. Esses assentamentos resultam da desapropriação ou da compra dos imóveis rurais.

Na microrregião de Sousa, foram criados 19 assentamentos, do ano de 1996 a 2011, totalizando uma área de 21225,4855 ha (Tabela 1). 
Tabela 1: Dados dos assentamentos criados na microrregião de Sousa no Sertão paraibano.

\begin{tabular}{|c|c|c|c|c|c|}
\hline Município & Assentamento & Área(ha) & $\begin{array}{l}\text { № de Famílias } \\
\text { (capac.) }\end{array}$ & $\begin{array}{c}\text { Famílias } \\
\text { Assentadas }\end{array}$ & $\begin{array}{l}\text { Ano de } \\
\text { Criação }\end{array}$ \\
\hline Aparecida & Acauã & $2.825,0368$ & 114 & 111 & $30 / 11 / 1996$ \\
\hline Aparecida & Angélicas & $1.440,0000$ & 34 & 34 & $31 / 10 / 2005$ \\
\hline Aparecida & Várzea de Sousa I & 100,7561 & 14 & 12 & $29 / 08 / 2006$ \\
\hline Aparecida & Veneza I & 635,9674 & 27 & 27 & $14 / 08 / 2007$ \\
\hline Aparecida & Angélica II & 993,6636 & 19 & 16 & $27 / 09 / 2010$ \\
\hline Aparecida & Nova Vida I & $1.007,0500$ & 141 & 141 & $24 / 01 / 2011$ \\
\hline Lastro & Jerimum & $1.019,9916$ & 51 & 50 & $27 / 09 / 2010$ \\
\hline Malta & $\begin{array}{l}\text { Padre Acácio } \\
\text { Cartaxo Rolim }\end{array}$ & 724,8000 & 19 & 19 & $16 / 06 / 2003$ \\
\hline Marizópolis & Juazeiro & $1.809,0338$ & 61 & 61 & $30 / 11 / 1999$ \\
\hline Paulista & Paxicu & $1.227,0000$ & 36 & 35 & $31 / 08 / 2004$ \\
\hline Paulista & Curralinho & $1.227,9000$ & 40 & 40 & $26 / 06 / 2003$ \\
\hline Pombal & Jacú & $1.200,0000$ & 40 & 40 & $16 / 03 / 2003$ \\
\hline Pombal & $\begin{array}{c}\text { Margarida Maria } \\
\text { Alves }\end{array}$ & 594,0000 & 46 & 46 & $20 / 07 / 2005$ \\
\hline Pombal & Santa Monica & $2.728,5161$ & 27 & 27 & $03 / 09 / 2008$ \\
\hline $\begin{array}{c}\text { São Domingos de } \\
\text { Pombal }\end{array}$ & Paissandu & $1.215,0000$ & 27 & 27 & $30 / 06 / 2010$ \\
\hline $\begin{array}{c}\text { São José da Lagoa } \\
\text { Tapada }\end{array}$ & Sarapo & 756,6000 & 36 & 35 & $24 / 08 / 2005$ \\
\hline Sousa & $\begin{array}{c}\text { Várzea de Sousa } \\
\text { II }\end{array}$ & 390,3787 & 75 & 67 & $29 / 08 / 2006$ \\
\hline Sousa & $\begin{array}{c}\text { Várzea de Sousa } \\
\text { III }\end{array}$ & 475,8027 & 89 & 83 & $29 / 08 / 2006$ \\
\hline Sousa & Zequinha & 853,9887 & 20 & 18 & $27 / 09 / 2010$ \\
\hline Totais & Total Assent: 19 & $\begin{array}{l}\text { Total Área: } \\
21225,4855\end{array}$ & Total Cap: 916 & $\begin{array}{l}\text { Total Fam. } \\
\text { assent: } 889\end{array}$ & \\
\hline
\end{tabular}

Fonte: INCRA - 2012.

Segundo os dados do INCRA, foi nessa microrregião onde ocorreu o maior número de assentamentos criados. Esses assentamentos vêm gerando emprego e renda para milhares de trabalhadores rurais, além de uma melhor qualidade de vida para todos. No assentamento acauã, localizado no município de Aparecida, sistemas de produção agrícola, do tipo Mandala, proporciona a produção de variadas hortícolas, que são comercializadas, pelos produtores, na feira do município. Nesse assentamento também foram construídas cisternas, escolas, quadra poli esportiva e posto de saúde (SILVA et al, 2017). 
Nas várzeas irrigadas do município de Sousa, vários produtores assentados vêm plantando diversas hortaliças de forma orgânica e tendo excelentes resultados. Pordeus et al. (2016), estudando esse projeto no município, aponta como principais ganhos econômicos os seguintes fatores: produção de diversas hortaliças, geração de emprego e renda, agregação de valor nos produtos e aquisição de equipamentos, e veículos para escoar a produção. Como ganhos sociais; o estudo aponta acesso à terra e água, Inserção nas políticas públicas, destinadas à agricultura familiar (PRONAF, PNAE e PAA), relações sociais entre os produtores e instituições de ensino, pesquisa e extensão rural.

Na microrregião de Catolé do Rocha, foram criados cinco assentamentos entre os anos 1997 e 2009, com área total de 6011,6555 ha, abrigando 220 famílias (Tabela 2). O município de Jericó, inserido nessa microrregião, foi palco de um marcante conflito pela posse da terra nos anos 90. Agricultores receberam terras por desapropriação do governo e os mesmos passaram a cultivar a terra e realizar benfeitorias. Logo após o processo, o governo revogou a decisão, devolvendo a administração das terras aos antigos donos, o que provocou inúmeros conflitos (SILVA, 1997).

Atualmente, agricultores dos assentamentos, Alto Alegre, Saquinho e Fortuna, plantam diversas culturas agrícolas, criam animais e contribuem de forma efetiva para economia do município. Recentemente, essas comunidades foram contempladas pelo projeto de fomento "Mulher e Semiárido", um programa de financiamento de quase 1,5 milhões de reais, destinado para o desenvolvimento da agricultura e qualidade de vida.

Tabela 2. Dados dos assentamentos criados na microrregião de Catolé do Rocha no Sertão paraibano.

\begin{tabular}{|c|c|c|c|c|c|}
\hline Município & Assentamento & Área(ha) & $\begin{array}{c}\text { No de Famílias } \\
\text { (capac.) }\end{array}$ & $\begin{array}{c}\text { Famílias } \\
\text { Assentadas }\end{array}$ & $\begin{array}{c}\text { Ano de } \\
\text { Criação }\end{array}$ \\
\hline Jericó & Cruzeiro/Saquinho & 794,3000 & 35 & 31 & $29 / 08 / 2001$ \\
\hline Jericó & Fortuna & $1.792,50000$ & 73 & 71 & $09 / 12 / 1997$ \\
\hline Jericó & Alto Alegre & 745,6000 & 45 & 45 & $11 / 12 / 1998$ \\
\hline Lagoa & Cantinho & 428,8091 & 38 & 38 & $11 / 02 / 2009$ \\
\hline Lagoa & Santa Monica I & $2.250,4464$ & 35 & 35 & $01 / 10 / 2009$ \\
\hline Totais & Total Assent: 5 & $\begin{array}{c}\text { Total Área: } \\
6011,6555\end{array}$ & $\begin{array}{c}\text { Total Capac.: } \\
226\end{array}$ & $\begin{array}{c}\text { Total Fam. } \\
\text { Assent.: } 220\end{array}$ \\
\hline
\end{tabular}

FONTE: INCRA - 2012.

Na microrregião de cajazeiras, foram criados 9 assentamentos entre os anos 1997 e 2010. O total de área desapropriada foi de 8524,4918 ha, assentando 238 famílias (tabela 3). 
No município de Cajazeiras, Freitas et al. (2013), estudando os assentamentos, Frei Damião, Frei Beda, Mãe Rainha, Santo Antônio e Valdeci Santiago, concluíram que o processo de reforma agrária não só melhorou a vida dos assentados, como contribuiu de forma efetiva com a economia do município. Segundo os resultados, são produzidos nesses assentamentos diversos tipos de vegetais e animais, que são comercializados nas feiras ou vendidos para pequenos e médios empresários do ramo alimentício da cidade. Os produtores também desenvolveram novas técnicas mais sustentáveis de agricultura e uso do solo para melhor conviver com o clima Semiárido.

No assentamento Bom Jesus, no município de Poço Dantas, em parceria com a prefeitura, foram instaladas hortas comunitárias onde os agricultores produzem: coentro, beterraba, pimentão, cenoura, cebolinha, tomate etc. o excedente da produção é comercializado em feiras livres das cidades vizinhas. Esse assentamento também foi contemplado com pavimentação, sendo um dos poucos no estado da Paraíba com esse benefício.

Tabela 3. Dados dos assentamentos criados na microrregião de Cajazeiras no Sertão paraibano.

\begin{tabular}{|c|c|c|c|c|c|}
\hline Município & Assentamento & Área (ha) & $\begin{array}{c}\text { No de Famílias } \\
\text { (capac.) }\end{array}$ & $\begin{array}{c}\text { Famílias } \\
\text { Assentadas }\end{array}$ & $\begin{array}{l}\text { Ano de } \\
\text { Criação }\end{array}$ \\
\hline $\begin{array}{c}\text { Poço } \\
\text { Dantas }\end{array}$ & Bom Jesus & 610,0500 & 22 & 22 & $11 / 02 / 2000$ \\
\hline $\begin{array}{l}\text { Cachoeira } \\
\text { dos índios }\end{array}$ & São Francisco II & 727,3000 & 21 & 21 & $22 / 12 / 1997$ \\
\hline Cajazeiras & Edvaldo Sebastião & 366,9549 & 19 & 18 & $17 / 08 / 2001$ \\
\hline Cajazeiras & Frei Damião & 726,0000 & 21 & 20 & $17 / 08 / 2001$ \\
\hline Cajazeiras & Frei Beda & $1.308,1200$ & 34 & 34 & $30 / 122004$ \\
\hline Cajazeiras & Mãe Rainha & 376,9909 & 28 & 28 & $06 / 03 / 2007$ \\
\hline Cajazeiras & Santo Antônio & 662,0200 & 32 & 32 & $02 / 12 / 1997$ \\
\hline Cajazeiras & Valdeci Santiago & $2.579,0000$ & 64 & 48 & $22 / 12 / 1997$ \\
\hline $\begin{array}{c}\text { Santa } \\
\text { Helena }\end{array}$ & Padre Cleuides & $1.168,0560$ & 16 & 15 & $27 / 09 / 2010$ \\
\hline Totais & Total Assent: 9 & $\begin{array}{l}\text { Total Área: } \\
8524,4918\end{array}$ & $\begin{array}{c}\text { Total Capac.: } \\
257\end{array}$ & $\begin{array}{c}\text { Total Fam. } \\
\text { Assent.: } 238\end{array}$ & \\
\hline
\end{tabular}

Fonte: INCRA, 2012. 
Na microrregião de Patos, foram assentadas, entre os anos 1997 e 2010, 640 famílias em 12 comunidades, somando uma área total de 9719431,24 ha. Essa microrregião foi a segunda colocada em quantidades de assentamentos criados no Sertão Paraibano (tabela 4).

Nessa microrregião, possui destaque o assentamento Patativa do Assaré, localizado no município de Patos. Esse assentamento produz várias culturas agrícolas e cria animais, adotando técnicas sustentáveis de produção, provando o nível de conscientização com as questões ambientais dos assentados. Essa comunidade também dispõe de uma Escola Municipal de Ensino Fundamental (EMEF), que é mantida pela Prefeitura Municipal de patos e reconhecida pelo Ministério da Educação (MEC) (LINS, 2013).

Tabela 4. Dados dos assentamentos criados na microrregião de Patos no Sertão paraibano.

\begin{tabular}{|c|c|c|c|c|c|}
\hline Município & Assentamento & Área (ha) & $\begin{array}{c}\text { No de Famílias } \\
\text { (capac.) }\end{array}$ & $\begin{array}{c}\text { Famílias } \\
\text { Assentadas }\end{array}$ & $\begin{array}{l}\text { Ano de } \\
\text { Criação }\end{array}$ \\
\hline Santa Terezinha & $\begin{array}{c}\text { Dom Expedito } \\
\text { Eduardo de } \\
\text { Oliveira }\end{array}$ & $1.379,9000$ & 50 & 50 & $29 / 11 / 2001$ \\
\hline Santa Terezinha & Nego Fuba & $2.189,0082$ & 30 & 30 & $29 / 09 / 2010$ \\
\hline Patos & $\begin{array}{c}\text { Campo } \\
\text { Comprido }\end{array}$ & $3.429,9000$ & 86 & 86 & 09/12/1997 \\
\hline Patos & $\begin{array}{c}\text { Patativa do } \\
\text { Assaré }\end{array}$ & $2.239,6000$ & 60 & 60 & $25 / 03 / 2004$ \\
\hline $\begin{array}{l}\text { São José de } \\
\text { Espinharas }\end{array}$ & Maria da Paz & $2.495,0000$ & 40 & 40 & $16 / 06 / 2003$ \\
\hline $\begin{array}{l}\text { São José de } \\
\text { Espinharas }\end{array}$ & Cachoeira & $2.100,9150$ & 40 & 39 & $10 / 09 / 2003$ \\
\hline $\begin{array}{l}\text { São José de } \\
\text { Espinharas }\end{array}$ & Osiel Alves & 970.0000 & 25 & 25 & $25 / 03 / 2004$ \\
\hline $\begin{array}{l}\text { São José de } \\
\text { Espinharas }\end{array}$ & Tiradentes I & $1.300,0000$ & 35 & 35 & $25 / 03 / 2004$ \\
\hline $\begin{array}{l}\text { São José de } \\
\text { Espinharas }\end{array}$ & Nova Santana & 980,0000 & 24 & 24 & $17 / 09 / 2004$ \\
\hline $\begin{array}{l}\text { São José de } \\
\text { Espinharas }\end{array}$ & Nova Espinharas & $1.939,9778$ & 58 & 58 & $10 / 08 / 2007$ \\
\hline $\begin{array}{l}\text { São José do } \\
\text { Bomfim }\end{array}$ & Tubarão & $1.098,0000$ & 67 & 67 & 06/08/1997 \\
\hline Cacimba de Areia & $\begin{array}{l}\text { Barragem da } \\
\text { Farinha }\end{array}$ & 278,9125 & 131 & 126 & $14 / 04 / 1997$ \\
\hline Totais & Total Assent: 12 & $\begin{array}{l}\text { Total Área: } \\
9719431,24\end{array}$ & Total Capac.: 646 & $\begin{array}{c}\text { Total Fam. } \\
\text { Assent.: } \\
640\end{array}$ & $-\cdots$ \\
\hline
\end{tabular}

Fonte: INCRA - 2012. 
As microrregiões de Piancó, Itaporanga e Serra de Teixeira tiveram os menores números de assentamentos criados no Sertão paraibano. Na microrregião de Catingueira, só foram criados três assentamentos entre os anos 2001 e 2007. Os mesmos possuem área total de 6111,3947 ha (tabela 5). Já na microrregião de Itaporanga, foram criados cinco assentamentos, entre 1996 e 2011, em uma área total de 3462,8033 ha (tabela 6). Por último, na microrregião de Serra de Teixeira, foram criados quatro assentamentos, entre 1987 e 2001, com área total de 1591,7563 ha (tabela 7).

Tabela 5. Dados dos assentamentos criados na microrregião de Piancó no Sertão paraibano.

\begin{tabular}{|c|c|c|c|c|c|}
\hline Município & Assentamento & Área(ha) & $\begin{array}{c}\text { No de Famílias } \\
\text { (capac.) }\end{array}$ & $\begin{array}{c}\text { Famílias } \\
\text { Assentadas }\end{array}$ & $\begin{array}{c}\text { Ano de } \\
\text { Criação }\end{array}$ \\
\hline Catingueira & $\begin{array}{c}\text { Padre Luciano } \\
\text { Dias de Morais }\end{array}$ & $2.934,0000$ & 36 & 42 & $17 / 08 / 2001$ \\
\hline Catingueira & São Sebastião & 803,0000 & 28 & 28 & $12 / 06 / 2002$ \\
\hline Catingueira & $\begin{array}{c}\text { Nossa Senhora } \\
\text { Aparecida }\end{array}$ & $2.374,3947$ & 65 & 65 & $12 / 03 / 2007$ \\
\hline Totais & Total Assent: 3 & $\begin{array}{c}\text { Total Área: } \\
6111,3947\end{array}$ & $\begin{array}{c}\text { Total Capac.: } \\
129\end{array}$ & $\begin{array}{c}\text { Total Fam. } \\
\text { Assent.: } 135\end{array}$ \\
\hline
\end{tabular}

Fonte: INCRA - 2012.

Tabela 6. Dados dos assentamentos criados na microrregião de Itaporanga no Sertão paraibano.

\begin{tabular}{|l|l|l|l|l|l|}
\hline Município & Assentamento & Área(ha) & $\begin{array}{l}\text { No de } \\
\text { Famílias } \\
\text { (capac.) }\end{array}$ & $\begin{array}{l}\text { Famílias } \\
\text { Assentadas }\end{array}$ & $\begin{array}{l}\text { Ano de } \\
\text { Criação }\end{array}$ \\
\hline Diamante & Lampião & $1.568,6636$ & 37 & 36 & $03 / 09 / 2009$ \\
\hline Diamante & Cabano & $1.053,2975$ & 46 & 46 & $03 / 09 / 2009$ \\
\hline Diamante & Joaquin Teotônio & 535,1641 & 26 & - & $04 / 07 / 2011$ \\
\hline Itaporanga & Cristo Redentor & 118,5081 & 5 & 5 & $03 / 09 / 2008$ \\
\hline $\begin{array}{l}\text { Pedra } \\
\text { Branca }\end{array}$ & Gravata & 187,1700 & 67 & 67 & $17 / 12 / 1996$ \\
\hline Totais & Total Assent: 5 & $\begin{array}{l}\text { Total Área: } \\
3462,8033\end{array}$ & $\begin{array}{l}\text { Total Capaci: } \\
181\end{array}$ & $\begin{array}{l}\text { Total Fam. } \\
\text { Assent.: } 154\end{array}$ & - ------ \\
\hline
\end{tabular}

Fonte: INCRA - 2012. 
Tabela 7: Dados dos assentamentos criados na microrregião a Serra de Teixeira no Sertão paraibano.

\begin{tabular}{|c|c|c|c|c|c|}
\hline Município & Assentamento & Área(ha) & $\begin{array}{c}\text { No de } \\
\text { Famílias } \\
\text { (capac.) }\end{array}$ & $\begin{array}{c}\text { Famílias } \\
\text { Assentadas }\end{array}$ & $\begin{array}{c}\text { Ano de } \\
\text { Criação }\end{array}$ \\
\hline Maturéia & Pedra Lavrada & 139,4426 & 23 & 23 & $15 / 12 / 1987$ \\
\hline Maturéia & $1^{\circ}$ de Maio & 288,4526 & 20 & 20 & $21 / 07 / 2005$ \\
\hline Maturéia & $\begin{array}{c}\text { Cachoeira de } \\
\text { Maturéia }\end{array}$ & 545,3611 & 15 & 15 & $15 / 12 / 1987$ \\
\hline Teixeira & Poços de Baixo & 618,5000 & 45 & 45 & $17 / 08 / 2001$ \\
\hline Totais & Total Assent: 4 & $\begin{array}{c}\text { Total Área: } \\
1591,7563\end{array}$ & $\begin{array}{c}\text { Total Capac.: } \\
103\end{array}$ & $\begin{array}{c}\text { Total Fam. } \\
\text { assenta: } 103\end{array}$ \\
\hline
\end{tabular}

Fonte: INCRA - 2012.

De modo geral, foi verificado que em 55 cidades do Sertão não foram realizados projetos de assentamento, o que corresponde a $66,27 \%$ da região. Assim, podemos dizer que a reforma agrária no Sertão foi de baixo impacto e que a ação da luta dos agricultores familiares sem terra, embora tenha causado modificações sobre a estrutura fundiária regional, não foi suficiente para modificar a concentração de terra que caracteriza a região do Sertão.

Ainda segundo os dados, os assentamentos no Sertão foram criados a partir de 1987 a 2011. Notamos, com isso, a importância que foi o fim da ditadura militar e o nascimento e ações dos movimentos de luta pela terra que surgem no estado da Paraíba nessa época, passando a organizar os agricultores para lutarem por terra.

Os anos com maior criação de assentamentos foi de 2003 a 2010, resultando em 34 assentamentos criados. Esse período corresponde ao governo do presidente Luiz Inácio Lula da Silva (Lula). O governo de Fernando Henrique Cardoso, de 1995 a 2003, foi responsável pela criação de 20 assentamentos. O governo de Dilma Rousseff, que iniciou em 2010, criou apenas 3 assentamentos em 2011. Com isso, foi no governo Lula que houve maior criação de assentamentos no Sertão Paraibano.

Os 60 assentamentos criados têm capacidades para abrigar 2.532 famílias, contudo só foram assentadas 2.447, restando, ainda, capacidade para mais 85 famílias e, 19 assentamentos estão com os números de famílias abaixo de suas capacidades, enquanto que apenas um está acima. Isso significa que ainda faltam famílias a serem assentadas nessas terras. As cidades com maior número de assentamentos criados foram Aparecida, com seis assentamentos, Cajazeiras com seis e São José dos Espinharas, também com seis assentamentos criados.

Em uma região pouco industrializada, e com poucas oportunidades de empregos, o parcelamento de terra se torna uma importante ferramenta no desenvolvimento. Como descrito, os assentamentos criados proporcionaram renda a milhares de produtores e aquecimento da economia municipal e regional, gerando mais empregos. A melhor qualidade de vida proporcionada influenciou na fixação dos trabalhadores 
rurais, evitando o êxodo e o crescimento desordenado das capitais; com isso, mais pessoas ficaram na mesorregião do Sertão paraibano, atuando como produtores e consumidores e, movimentando ainda mais a economia da região.

\section{Considerações finais}

Mesmo com a criação de vários assentamentos no Sertão paraibano, a terra ainda é bastante concentrada, necessitando de mais projetos para melhor democratizar a terra na mesorregião. A criação de assentamentos rurais proporcionou inúmeros benefícios econômicos e sociais para os municípios sertanejos. Embora os projetos do INCRA tenham alcançado importantes resultados para os agricultores e para modificar a estrutura agrária no Sertão paraibano, ainda é preciso reivindicar melhores condições e perspectivas nos assentamentos rurais, para que os agricultores passem a melhorar cada vez mais seus sistemas produtivos.

\section{Referências}

ALVEAL, C. M. O; BARBOSA, K. B. C. A legitimidade da graça: os impactos da tentativa de reforço da política sesmarial sobre as terras da Casa da Torre na capitania da Paraíba (século XVIII).Topoi (Rio J.), Rio de Janeiro, v. 16, n. 30, p. 78-100, Junho de 2015.

ANDRADE, M. C. A terra e o homem no Nordeste: contribuição ao estudo da questão agrária no Nordeste. 7 ed. São Paulo: Cortez, 2005.

ARANHA, G. B. Campina Grande no espaço econômico regional: estradas de ferro, tropeiros e empório comercial algodoeiro (1907-1957) (Tese de Mestrado em Sociologia Rural). João Pessoa: UFPB, 1991.

BRASIL. Sistema de Informações dos Projetos de Assentamento da Reforma Agrária - SIPRA/INCRA (2010), Incra, 2010. Disponível em: <www.incra.gov.br>. Acesso em: Out 2014.

CARON, P; SABOURIN, E. Camponeses do sertão: mutação das agriculturas familiares no nordeste do Brasil. $1^{\text {a }}$ ed. Brasília: Embrapa, 2003.

FREITAS, J. P., PATRÍCIO, M. D. C. M., DE FREITAS, F. E., NETO, M. F. D. S., SILVA, V. M. D. A. (2013). Lutas camponesas no alto sertão e a questão ambiental: a busca da sustentabilidade no assentamento Santo Antônio, no município de Cajazeiras/PB. POLÊM! CA, 12(1), 137-147.

GETEC, Relatório DATALUTA 2014, Banco de Dados da Luta Pela Terra, Departamento de Geociências, UFPB, 2015. LINS, Lucicléa Teixeira. Autogestão e utopia na práxis dos movimentos sociais. 2013. 197 f. Tese (Doutorado em Educação) - Universidade Federal da Paraíba, João Pessoa, 2013. 
MOREIRA, E; TARGINO, I. Capítulos de Geografia Agrária da Paraíba, João Pessoa: Editora Universitária/UFPB, 1996

MOREIRA, E. . Por um Pedaço de Chão. João Pessoa: Editora Universitária/UFPB, 1997.

NOGUEIRA, F. R. B.; SIMÕES, S. V. D. Uma abordagem sistêmica para a agropecuária e a dinâmica evolutiva dos sistemas de produção no nordeste semiárido. Revista Caatinga, Mossoró, v. 22, n. 2, p. 1-6, 2009.

OLIVEIRA, S. G. Caminhos da Reforma Agrária: O Processo Histórico da Reforma Agrária no Alto Sertão Paraibano, da Luta Pela Terra a Luta Pela Terra (1985-2002). Dissertação (Mestrado em História) $\bigotimes$ Universidade Federal da Paraíba, Centro de Ciências Humanas, Letras e Artes, João Pessoa 2013.

PEREIRA, W. E. N. breves notas acerca da formação histórico-econômica de campina grande: do gado (século XIX) ao algodão (século XX). Revista História Econômica e História de Empresas. V. 19, n. 2, p. 295-346 (2017).

PORDEUS, G.O., MOREIRA, A., ARAUJO, K.F., ALVARENGA, C.F., SOUSA, F.D., BONIFÁCIO, B.F., SOUSA, F.M. (2016). Aspectos Socioeconômicos da produção orgânica de hortaliças nas várzeas de Sousa - Paraíba. INTESA - Informativo técnico do semiárido (Pombal-PB), v 10, n 1, p 01-04, janeiro -junho, 2016.

SILVA, A. P. da; Da sombra do juazeiro à luz elétrica ou como iluminaram-se as consciências: a construção da cidadania. (Dissertação de Mestrado em Sociologia). Campina Grande: UFPB. 1997.

SILVA, O.A.R.;COSTA, F. A.;RAPOSO, G. J. Movimento Social: As Conquistas Do MST do assentamento Acauâ no município de Aparecida - PB. IV CONGRESSO NACIONAL DE EDUCAÇÃO A Educação brasileira: desafios na atualidade. 15 a 18 de Novembro de 2017 - João Pessoa - PB. Anais... 